\title{
STABILIZATION OF CCA-CONTAMINATED SOIL WITH IRON PRODUCTS - A FIELD EXPERIMENT
}

\author{
Christian Maurice \\ Björn Gustavsson \\ Jurate Kumpiene \\ Sofia Lidelöw \\ Luleå University of Technology, Sweden
}

\begin{abstract}
Chemical stabilization of metals is lately considered as a possible pretreatment for soil contaminated with average levels of trace elements. The element mobility in soil can be altered by adding soil amendments that can adsorb, complex, or co-precipitate trace elements. As a consequence, pollutant spreading from the contaminated soil and effect on the recipient can be reduced. The different contaminants originating from wood impregnation chemicals, e.g. $\mathrm{Cu}, \mathrm{Cr}$, and $\mathrm{As}$ limit the choice of amendments because e.g. large $\mathrm{pH}$ fluctuations and consequent mobilization of $\mathrm{Cu}$ or As should be avoided. The results show that the leaching of arsenic is lowest in the lysimeter with $15 \% \mathrm{Fe}_{3} \mathrm{O}_{4}$. In both lysimeters with untreated soil and with $1 \% \mathrm{Fe}^{0}$, the arsenic leaching seems to decrease with the sampling depth. The leaching of copper is generally low. Further the addition of iron seems to increase the leaching of manganese and nickel but to reduce the leaching of zinc. Results from the laboratory experiment show that the arsenic content in the leachate is lowest with the highest mixture of magnetite. Mixing is one of the key issues when discussing the treatment efficiency and possible use of the treated soil. The results so far indicate that magnetite can be used for treatment of CCA contaminated soil also at a large scale. Reduction of both arsenic and copper using a single amendment is challenging as they behave opposite. Magnetite seems to be a promising amendment even though a high amount of amendment needs to be added. Moreover, the potential establishment of reducing conditions at larger depths in the soil is of concern since this might lead to a rapid increase in arsenic leaching.
\end{abstract}

\section{KEYWORDS}

Metallic iron; Stabilization; Arsenic; Copper; Chromium

\section{INTRODUCTION}

Chemical stabilization of metals is lately considered as a possible pretreatment for soil contaminated with average levels of trace elements. The element mobility in soil can be altered by adding soil amendments that can adsorb, complex, or co-precipitate trace elements $[1,2]$. 
Soil in areas related to forestry and wood processing are often polluted as a result of the industrial activity. A common example is the different contaminants originating from wood impregnation chemicals, e.g. $\mathrm{Cu}, \mathrm{Cr}$, and $\mathrm{As}$ (CCA). It is often easy to identify amendments for specific pollutants but the mixture of pollutants in CCA contaminated soils limits the choice of amendments because e.g. large $\mathrm{pH}$ fluctuations and consequent mobilization of $\mathrm{Cu}$ or As should be avoided [3, 4].

Iron amendments are suggested for remediation of As contaminated soil because Fe oxides can effectively sorb As in soil and reduce its mobility, availability and phytotoxicity $[5,6,7$, $8,9]$.

In previous work treatment with iron grit was shown to significantly reduce the leaching of all target elements at the cumulative liquid-to-solid ratio of 10 by $98 \%$ for As, $91 \%$ for $\mathrm{Cu}$, and $45 \%$ for $\mathrm{Cr}[1,3,4]$. The investigated soil was a sandy acidic soil ( $\mathrm{pH} 4.6$ in the soil solution) highly contaminated with As (5904 mg/kg), Cr $(3829 \mathrm{mg} / \mathrm{kg})$, and $\mathrm{Cu}(1509 \mathrm{mg} / \mathrm{kg})$, exceeding the generic guideline values for contaminated soils in Sweden with several orders of magnitude. Laboratory experiments also showed that other iron products, for example magnetite, could be a viable option for the stabilization.

The aim of this study is to implement the results from previous laboratory studies at an industrial scale. The investigation has two main focuses (1) the mixing and homogenization of the treated soil and (2) the sustainability of the treatment in a long term perspective. Laboratory and field studies are conducted in parallel to assess the element stability. This article present and discuss the set up of the experiment. Further the results from the first sampling campaigns are presented as a preliminary assessment of the treatment.

\section{MATERIAL AND METHODS}

\subsection{Soil characterisation}

The soil was collected at a former wood impregnation site in Northern Sweden (Table 1). Total decomposition of the soil was made in microwave oven (Mars 5) using Aqua Regia (1:10 soil to acid ratio) and analysed with ICP-OES (Perkin Elmer Optima 2000 DV).

Soil pH, oxidising-reducing potential (Eh) and electrical conductivity (EC) were measured in 1:2 soil-double distilled water $\left(\mathrm{ddH}_{2} \mathrm{O}\right)$ suspensions. Soil texture was determined using a hydrometer method. Total cation exchange capacity (CEC) was determined by a ammonium acetate method [10]. Total carbon (TC) of the bulk soil was determined using TOCVCPH/CPN (Shimadzu Corporation, Kyoto, Japan).

A screening test was done to evaluate the magnetite efficiency on the arsenic leaching. The tested mixing rates were $5,10,15,20$ and $25 \% \mathrm{Fe}_{3} \mathrm{O}_{4}$. A control without iron and a reference sample with $1 \%$ iron grit $\left(\mathrm{Fe}^{0}\right)$ were done. Batch leaching tests was used to evalutate the tretment. Soil was mixed with water acidified to $\mathrm{pH}=4$ with $1 \mathrm{M} \mathrm{HNO}_{3}$ at $\mathrm{L} / \mathrm{S} 10$ and agitated for $24 \mathrm{~h}$ using an end-over tumbler. The samples were filtered through a $0.45 \mu \mathrm{m}$ nitrocellulose membrane filter and immediately analyzed for trace elements by ICP-OES (Perkin Elmer Otima 2000 DV).

Field and laboratory experiments were started in parallel in June 2005 using the same iron types and soil. 
Table 1. Main characteristics of the untreated soil. $\pm S D, n æ 3$.

\begin{tabular}{|c|c|c|}
\hline & Unit & Untreated Soil \\
\hline $\mathrm{pH}\left(1: 2 \mathrm{H}_{2} \mathrm{O}\right)$ & - & $6.02 \pm 0.01$ \\
\hline Electrical conductivity (EC) & $\mu \mathrm{S} \mathrm{cm}{ }^{-1}$ & $439 \pm 26$ \\
\hline Oxidising-reducing potential (Eh) & $\mathrm{mV}$ & $278 \pm 20$ \\
\hline Total solids (TS) & $\%$ & $88.1 \pm 1.8$ \\
\hline Loss on ignition (LOI) & $*$ & $1.2 \pm 0.0$ \\
\hline Total carbon (TC) & " & $0.93 \pm 0.07$ \\
\hline Cation exchange capacity (CEC) & $\mathrm{cmol} \mathrm{kg}^{-1}$ & $5.04 \pm 0.26$ \\
\hline Water holding capacity (WHC) & $\%$ & 39.8 \\
\hline Texture (sandy loam) & " & \\
\hline Sand & " & 69.5 \\
\hline Silt & "* & 28.5 \\
\hline Clay & “ & 2.0 \\
\hline Elements (total concentration) & $\mathrm{mg} \mathrm{kg}^{-1} \mathrm{dw}$ & \\
\hline As & - & $310.1 \pm 17.4$ \\
\hline $\mathrm{Cr}$ & " & $62.8 \pm 10.8$ \\
\hline $\mathrm{Cu}$ & " & $15.5 \pm 0.2$ \\
\hline $\mathrm{Zn}$ & " & $132.6 \pm 6.7$ \\
\hline $\mathrm{Ni}$ & & $11.6 \pm 0.2$ \\
\hline $\mathrm{Mn}$ & " & $330.6 \pm 15.6$ \\
\hline
\end{tabular}

\subsection{Field experiment}

The field experiment was started in June 2005 to evaluate the treatment technique at a larger scale. Forty tons of CCA-contaminated soils were mixed with two different iron products, iron grit and magnetite, at four levels. The mixing was done in two steps (Figure 1) using first a screener crusher ( $a$ and $b$ ) and second a rotating single skin trommel ( $c$ and d).

Figure 2 summarizes the sampling of soil and water. A stratified random sampling [11] was performed after each step to assess the mixing (e). First, a representative sample size needs to be determined [12]. Several methods are suggested and will be evaluated and compared based on their results, reliability and ease to use [13]. When this step is performed samples can be taken to determine the quality of the mixing process. About 1.3 tonnes of treated soil were placed in six lysimeters (f) that have been monitored since August 2005. Each lysimeter is equipped with four pore water samplers (Rhizons) comparable to the one used in the laboratory experiment. Samples $(\mathrm{g})$ are taken each month and analyzed for their content of trace elements and iron. 
a)

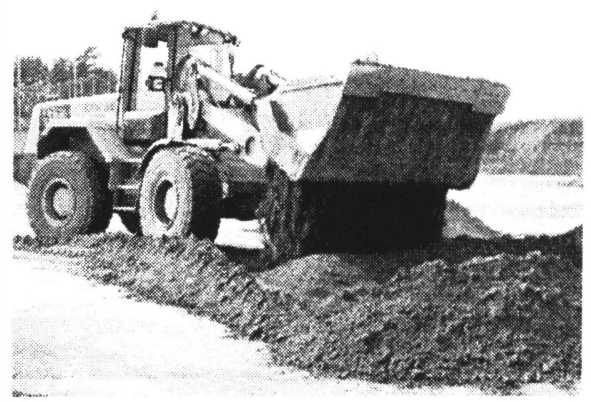

c)

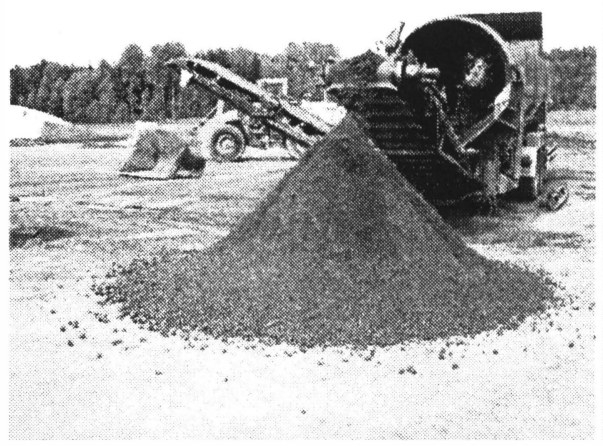

b)

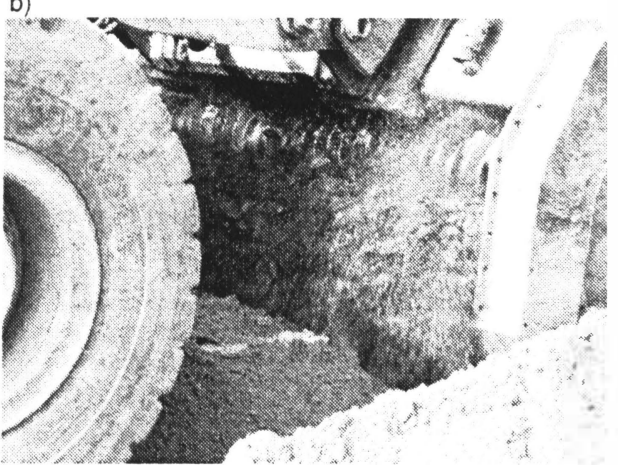

d)

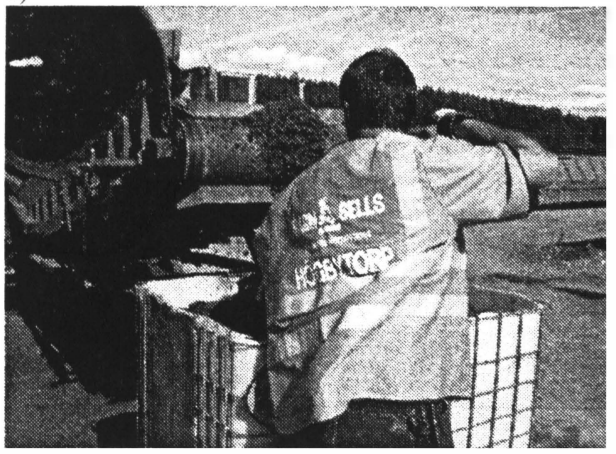

Figure 1. Mixing of the amendment and the soil.

e)

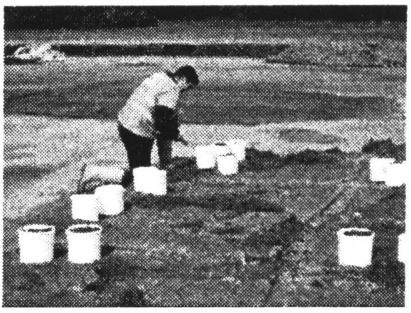

f)

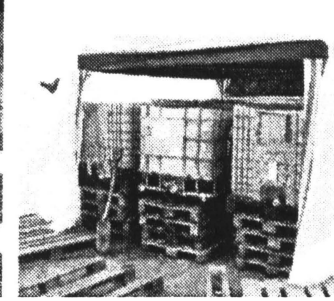

g)

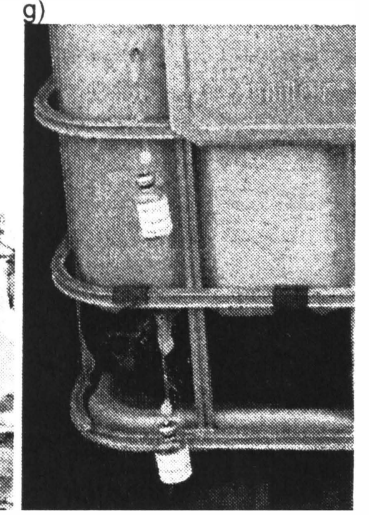

Figure 2. Sampling of soil and water in the lysimeters. 
The mixing of iron resulted in six different lysimeters containing different types of soil-iron mixtures. Certain lysimeters are watered while other are kept dry. Dry means that the lysimeters are watered once a month with 10 liters of water. Water holding capacity means that the lysimeters are watered 5 times a week with 10 liters of water which leaches freely from the lysimeter. The lysimeters are marked according to the following denomination:

- A - untreated soil, dry

○ B - untreated soil, water holding capacity

- $\mathrm{C}$ - soil treated with $1 \% \mathrm{Fe}^{0}$, dry

- $\mathrm{D}$ - soil treated with $1 \% \mathrm{Fe}^{0}$, water holding capacity

- $\mathrm{E}$ - soil treated with $7 \% \mathrm{Fe}_{3} \mathrm{O}_{4}$, water holding capacity

○ $\mathrm{F}$ - soil treated with $15 \% \mathrm{Fe}_{3} \mathrm{O}_{4}$, water holding capacity

The results presented here focuses on lysimeters $\mathrm{B}, \mathrm{D}$ and $\mathrm{F}$.

\subsection{Laboratory experiment}

Soil from each container was split into three piles according to a fractional shovelling method (h) [12]. Further, all soil-iron mixtures containing and the control samples with only contaminated soil were homogenised in a concrete blender ( $\mathrm{i}$ and j) (Figure 3).

Control samples: Control samples, containing only contaminated soil, were homogenised in the concrete blender according to the same procedure as the other soils. Each time $40 \mathrm{~kg}$ of soil was homogenised for $15 \mathrm{~min}$ and placed into $15 \mathrm{l}$ buckets (13 kg of soil in each bucket).

h)

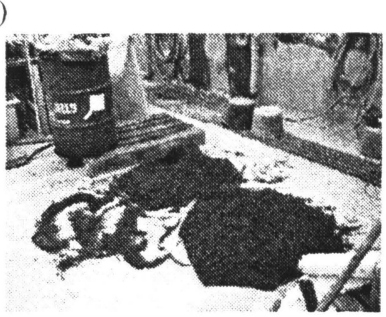

i)

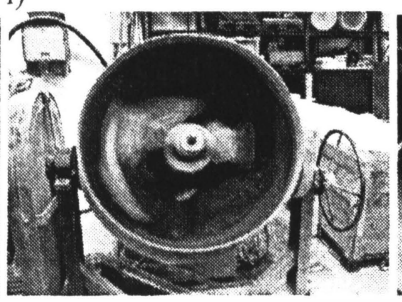

j)

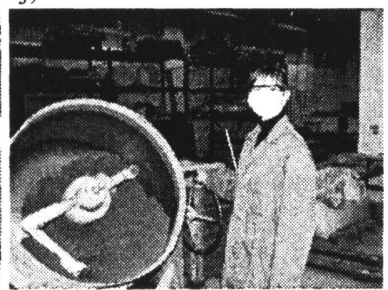

Figure 3. Mixing of the material for laboratory experiments.

Soil and magnetite mix: Fresh magnetite $\left[\mathrm{Fe}_{3} \mathrm{O}_{4}\right]$ was received one day before the mixing. The mixing was performed in the same way as the homogenisation of the control samples, i.e. soil was placed into the concrete blender and while rotating mixed with magnetite. The amount of magnetite added ws 1,7 and $15 \%$.

Soil and zerovalent iron mix: Zerovalent iron $\left[\mathrm{Fe}^{0}\right]$ was mixed with soil in the same manner as magnetite. The amount of Fe added was 0.1 and $1 \%$.

Water was added to the mixtures to reach approximately $50 \%$ of the water holding capacity. All soil mixtures were placed in the same room and loosely covered to reduce water evaporation. The water content was controlled by a gravimetric method during two weeks period. Two weeks later, an appropriate amount of water (according to the factorial design) was added to the buckets and mixtures were transferred to new buckets containing Rhizons. 


\section{RESULTS AND DISCUSSION}

The results from the screening test are presented in Figure 4. Magnetite added to the soil at a rate of $5-25 \%$ reduced the arsenic leaching by $85-95 \%$. Iron grit $\left(\mathrm{Fe}^{0}\right)$ used as reference material reduced the arsenic leaching by $99 \%$.

0.2

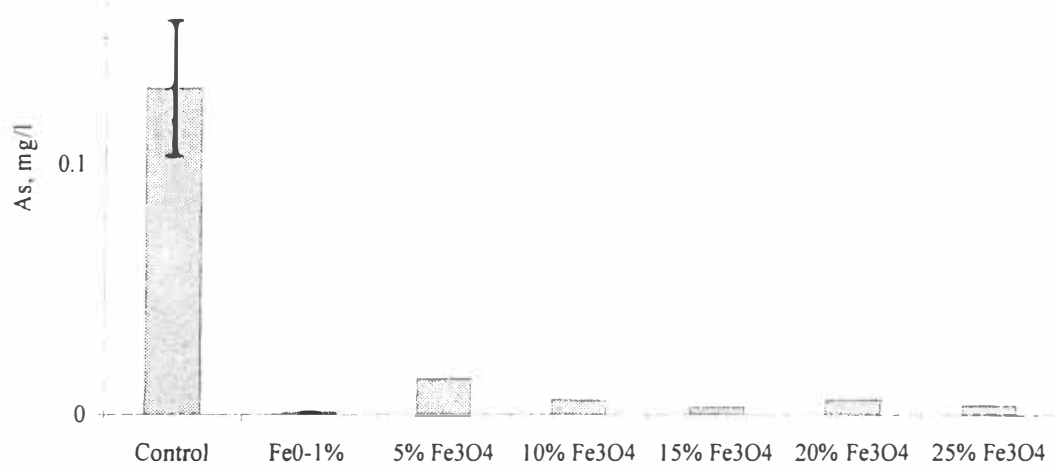

Figure 4. Results from the screening test with different magnetite concentrations.

\subsection{Field experiment}

After two months of watering, the lysimeters had reached an L/S ratio of 0.6 . The results from metal analysis of the samples show that the leaching of arsenic is lowest in the lysimeter with $15 \% \mathrm{Fe}_{3} \mathrm{O}_{4}$ (Figure 5). The arsenic leaching was reduced with $1 \% \mathrm{Fe}^{0}$ but is not as low as expected from previous laboratory experiments $[1,3,4]$. One hypothesis is that the mixing of $1 \%$ iron was not as successful as the mixing of $15 \%$ magnetite and that the iron is poorly distributed in the soil. In both the lysimeter with untreated soil and with $1 \% \mathrm{Fe}_{0}$, the arsenic leaching seems to decrease with the sampling depth.

The leaching of copper is generally low. The lowest concentration was found in the lysimeter with $1 \% \mathrm{Fe}^{0}$. A sudden increase in copper leaching was however observed at the lowest sampling point (F10) with $220 \mu \mathrm{g} / \mathrm{l}$ in the lysimeter with $15 \% \mathrm{Fe}_{3} \mathrm{O}_{4}$.

The leaching of manganese, nickel, and zinc increases with sampling depth. The addition of iron seems to increase the leaching of manganese and nickel but to reduce the leaching of zinc. Likely, the manganese and the nickel found in the pore water partly originates from the iron grits added, though the soil in itself also contains high amounts of manganese (Table l). The nickel concentration seems to increase with the amount of iron grit added and is verya high (about $2000 \mu \mathrm{g} / \mathrm{l}$ ) in the lysimeter with $15 \%$ magnetite.

The amount of iron and chromium in the pore water was generally low in all lysimeters. The iron concentration in both the lysimeter with $1 \% \mathrm{Fe}^{0}$ and the one with $15 \% \mathrm{Fe}_{3} \mathrm{O}_{4}$ was generally below the detection limit of the analysis. Only a few $\mu \mathrm{g} / \mathrm{l}$ of chromium were leached from the untreated soil and from the amended soils the pore water concentrations were even lower. 


\section{After 2 months of leaching (L/S 0.6)}

100000

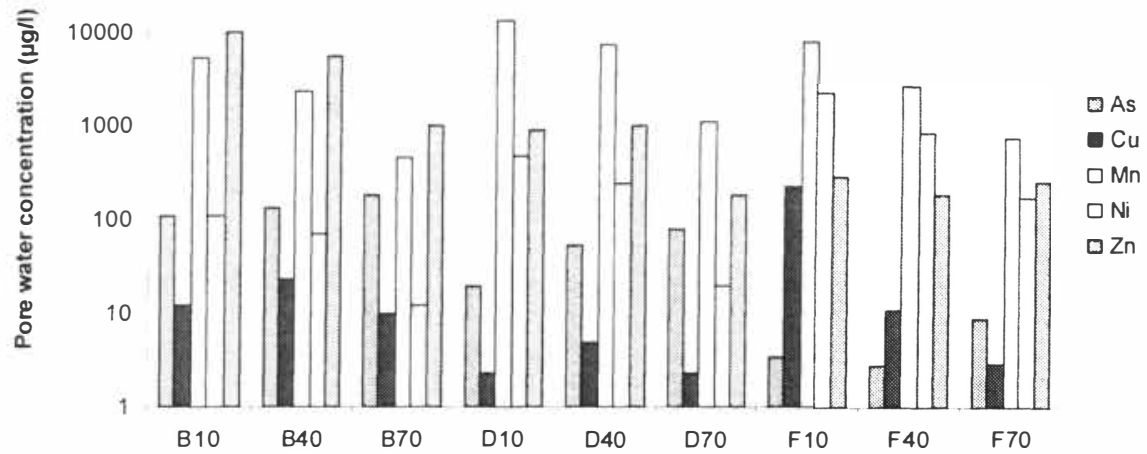

Figure 5. Element concentrations in pore water after two months (L/S 0.6). Samples are taken at three depths (10, 40 and $70 \mathrm{~cm}$ from the bottom) in three lysimeters that are watered at water holding capacity (B: untreated, $\mathrm{D}: 1 \% \mathrm{Fe}^{0}$ and $\mathrm{F}: 15 \% \mathrm{Fe}_{3} \mathrm{O}_{4}$ ).

Similar results were obtained from the first sampling campaign at L/S 0.4 . The leaching of copper seems to have increased compared with the first sampling campaign, whereas the leaching of zinc has decreased somewhat. However, more data are needed to be able to assess the impact of time on the emissions of contaminants.

The results so far indicate that magnetite can be used for treatment of CCA contaminated soil also at a large scale. However, the mixing of soil and amendments is a critical step, especially when small amounts of amendments are added. Moreover, the potential establishment of reducing conditions at larger depths in the soil is of concern since this might lead to a rapid increase in arsenic leaching. No such effects were noted in the lysimeters during the first sampling campaigns, rather the contrary, but might occur over time.

\subsection{Laboratory experiment}

Results from the laboratory experiment show that the arsenic content in the leachate is lowest with the highest mixture of magnetite (Figure 6). However, it leads to copper leaching by one order of magnitude higher than the control and the copper concentration also increases with the iron mixing rate.

Leaching of chromium is very low both with $1 \%$ iron and $15 \%$ magnetite. However, chromium is seldom a problem in such applications as its mobility is low [3,4]. Leaching of zinc is not affected by the treatment.

The effect of iron grit was lower than expected [1, 4] and Figure 4. Results from the screening tests showed iron grit to be very efficient to reduce arsenic leaching. Uneven mixing may explain the low arsenic reduction. Further, the effect of the mixing rate is observable as the amendment with $0.1 \%$ iron does not affect the leaching of elements. The amount of iron added is enough on a stochiometric basis, so a bad mixing is the most probable reason for the imperceptible effiect. 
10000

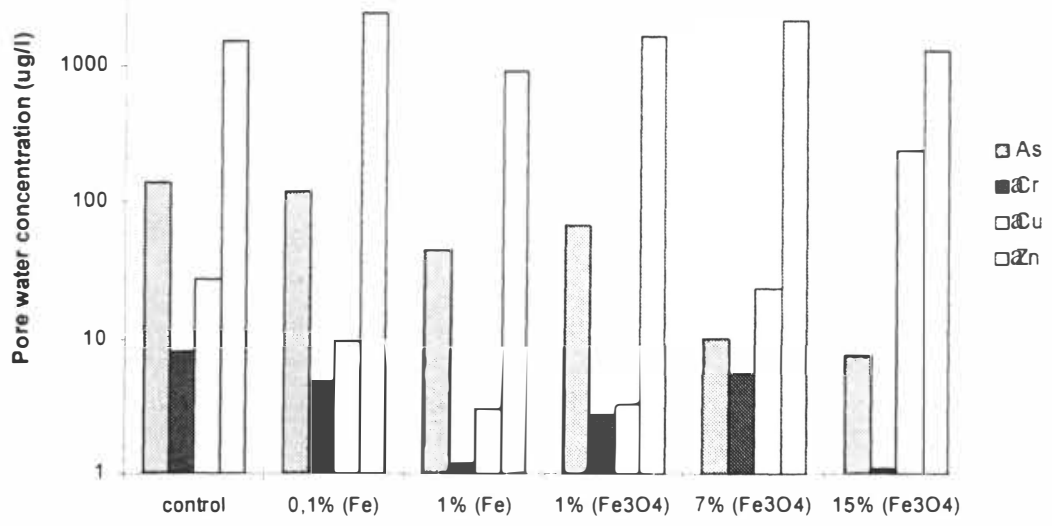

Figure 6. Element concentrations in pore water after two month in buckets at 50\% water holding capacity containing different concentrations of iron.

Reduction of both arsenic and copper leaching using a single amendment is challenging $[3,4]$ as they behave opposite. Magnetite seems to be a promising amendment even though a high amount of material needs to be added. Both laboratory and filed experiment show the most promising results concerning arsenic reduction with $15 \%$ magnetite mixing.

\subsection{Stabilization as a treatment method}

On-going work on the characterisation of the mixing is expected to give answer on how well the amendment mixing was done. Ocular assessment revealed that iron aggregates occurred after the first mixing step (Figure 7). However, such aggregates were not visible after the second mixing step.

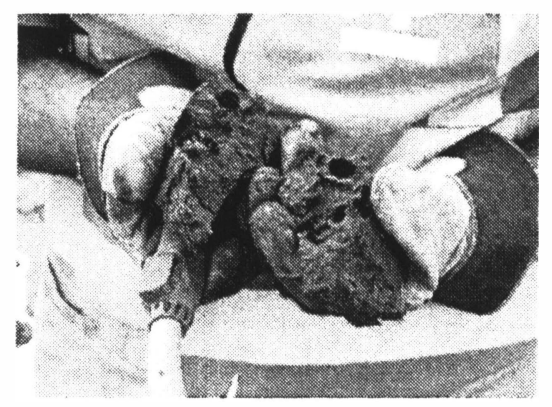

Figure 7. Soil samples after the first mixing step. 
Mixing is one of the key issues when discussing the treatment efficiency and possible use of the treated soil [14]. As observed both in the laboratory and the field experiment, the mixture with high rates of amendment are more successful even though there is enough iron in all mixtures even at the lowest addition rates. Likely, more soil particles get in contact with iron particles at higher concentrations. It is not possible to draw conclusions after only one sampling campaign. However, the efficiency of the $\mathrm{Fe}^{0}$ is lower than expected. Result from previous research work let expect $\mathrm{Fe} 0$ to be the most efficient amendment $[1,6,15]$. Possible use for the treated soil would be as secondary construction materials [14] at landfills e.g. as cover materials [16] or in situ, i.e. at the brownfields $[6,7,17]$. The research continues focusing on the sustainability of the treatment and the effect of environmental factors on the treated soil.

\section{CONCLUSIONS}

The results from metal analysis of the samples show that the leaching of arsenic is lowest in the lysimeter with $15 \% \mathrm{Fe}_{3} \mathrm{O}_{4}$. In both lysimeters with untreated soil and with $1 \% \mathrm{Fe}^{0}$, the arsenic leaching seems to decrease with the sampling depth. The leaching of copper is generally low. Further the addition of iron seems to increase the leaching of manganese and nickel but to reduce the leaching of zinc.

Results from the laboratory experiment shows that the arsenic content in the leachate is lowest with the highest mixture of magnetite. The effect of iron grit was lower than expected. Results from the screening test showed iron grit to be very efficient in reducing arsenic leaching.

Mixing is one of the key issues when discussing the treatment efficiency and possible use of the treated soil. Uneven mixing may explain the low arsenic reduction observed. The results so far indicate that magnetite can be used for treatment of CCA contaminated soil also at a large scale. However, the mixing of soil and amendments is a critical step, especially when small amounts of amendments are added.

Both laboratory and field experiment show that magnetite seems to be a promising amendment even though a high amount of material needs to be added $(15 \%$ magnetite mixing). However reduction of both arsenic and copper using a single amendment is challenging as they behave opposite. Moreover, the potential establishment of reducing conditions at larger depths in the soil is of concern since this might lead to a rapid increase in arsenic leaching.

\section{ACKNOWLEDGEMENTS}

The work is financially supported by European Union Structural Funds and New Objective 1, North Sweden Soil Remediation Center (MarksaneringsCentrum Norr - MCN), contract no. 113-12534-00, and performed in cooperation with Ragn-Sells Avfallsbehandling $A B$.

\section{REFERENCES}

[1] Kumpiene, J., Ore, S., Renella. G., Mench, M., Lagerkvist, A., Maurice C. Assessment of zerovalent iron for stabilisation of $\mathrm{Cr}, \mathrm{Cu}, \mathrm{As}$ in soil. Environmental Pollution. Accepted.

[2] Kumpiene, J.. Role of soil organic matter in the immobilization of metals - Treatment of leachate from MSWI bottom ash. Licentiate Thesis 2003:62. Luleå University of Technology, Sweden. 
[3] Montesinos Isaac Castillo, 2005. Stability assessment of iron treated CCA contaminated soil. Master Thesis 2005:096 Luleå University of Technology, Luleå, Sweden.

[4] Lundberg Eleonor, 2004. Stabilisation of CCA-contaminated soil: assessment of amendments for immobilization of chromate cupper arsenate (CCA). Master Thesis 2004: 303, Luleå University of Technology, Luleå, Sweden.

[5] Jain, A., Raven, K.P., Loeppert, R.H., 1999.. Arsenite and arsenate adsorption on ferrihydrite: surface charge reduction and net $\mathrm{OH}^{-}$release stoichiometry. Environ. Sci. Technol. 33, 1179-1184.

[6] Mench, M., Vangronsveld, J., Cli.jsters, H., Lepp, N.W., Edwards, R., 2000. In situ metal immobilisation and phytostabilisation of contaminated soils. In: Norman, T., Banuelos, G.. Phytoremediation of contaminated soil and water. Lewis Publishers, Boca Raton, FL, p. 389.

[7] Mench, M. Bussiere, S., Boisson, J., Castaing, E., Vangronsveld, J., Ruttents, A., De Koe, T., Bleeker, P., Assuncao, A., Manceau, A., 2003. Progress in remediation and revegetation of the barren Jales gold mine spoil after in situ treatment. Plant and soil 249, 187-202.

[8] Warren, G.P., Alloway, B.J., Lepp, N.W., Singh, B., Bochereau, F.J.M., Penny. C., 2003. Field trials to assess the uptake of arsenic by vegetables from contaminated soils and soil remediation with iron oxides. The Science of the Total Environment 311, 19-33.

[9] Warren, G.P., Alloway, B.J., 2003. Reduction of arsenic uptake by lettuce with ferrous sulfate applied to contaminated soil. Journal of Environmental Quality 32(3), 767-772.

[10] Lavkulich, L.M., 1981. Exchangeable cations and total exchangeable capacity by the ammonium acetate method at pH 7.0. In: Carter, M.R. (Ed) 1993. Soil sampling and methods of analysis. Lewis Publishers, Boca Raton, FL, p. 823.

[11] Luthbom K., Uncertainty in environmental decision-making - effiects of defined or undefined guidance in the decision process. Licentiate Thesis 2004:64, Luleå University of Technology, Sweden.

[12] Pitard, F.F., 1993. Pierre Gy's sampling theory and sampling practice: heterogeneity, sampling correctness, and statistical process control, CRC Press, Boca Raton, p. 488.

[13] Gustavsson Björn, Estimating and reducing errors in soil sampling. Licentiate Thesis 2004:47, Luleå University of Technology, Sweden

[14] Lidelöw S., 2004. Environmental assessment of secondary construction material. Licentiate Thesis 2004:65, Luleå University of Technology, Sweden

[15] Hartley, W., Edwards, R., Lepp, N.W., 2004. Arsenic and heavy metal mobility in iron oxide-amended contaminated soils as evaluated by short- and long-term leaching tests. Environmental Pollution 131, 495-504.

[16] Maurice, C., 2001. Bioindication and bioremediation of landfill emissions. Doctoral Thesis. Division of Waste Science and technology, Department of Environmental Engineering, Luleå University of Technology, Luleå, Sweden.

[17] Maurice, C., Lagerkvist, A., 2000. Using Betula pendula and Telephora caryophyllea for soil Pollution Assessment. Journal of Soil Contamination 9 (1), 31-50. 